\title{
Corrupción y gestión migratoria en el México posrevolucionario
}

\author{
por \\ Pablo Yankelevich* \\ Instituto Nacional de Antropología e Historia
}

En este trabajo se estudia la naturaleza, extensión y significados de prácticas de corrupción en el Servicio de Migración de México durante las primeras décadas del siglo XX. Se advierten las maneras en que la corrupción creció al amparo de un ensanchamiento de las regulaciones migratorias y el control fronterizo, en un contexto en que la necesidad de ingresar o salir de país por parte de extranjeros y mexicanos era valorada como una oportunidad para enriquecimientos ilícitos. La dimensión alcanzada por estas prácticas permite valorarlas como parte consustancial del orden político antes que como un asunto de carácter moral.

Palabras Clave: México; migración; corrupción; administración pública; siglo XX.

«México sigue sufriendo las consecuencias de una ineficaz, corrompida e viciosa administración pública» sentenció Wendell Karl Gordon Schaeffer en un ya clásico estudio publicado a mediados del siglo pasado ${ }^{1}$. Para este experto en la gestión administrativa, cualquier mejoramiento en el servicio público suponía la puesta en marcha de un programa fundado en la moralización y la fiscalización. Moralizar, decía, supone la eliminación de la deshonestidad general y de la institución de la «mordida»; mientras que la fis-

* Este trabajo se inscribe en el proyecto de investigación «Nación y Extranjería en México» financiado por el Consejo Nacional de Ciencia y Tecnología de México (CB151011). Por la ayuda en la búsqueda de fondos documentales y en el diseño de la gráfica incluida en este texto, agradezco a Efraín Navarro, Carlos Inclán, Paola y Déborah Chenillo y a Beatriz Gaytán. Por último, dejo constancia de mi agradecimiento a los colegas del Seminario de Historia de la Revolución Mexicana de El Colegio de México, por sus comentarios a versiones previas de este artículo.

1 Gordon Schaeffer VII / 1 (México, 1955): 288. 
calización implica el establecimiento de controles que impidan la fuga de ingresos y de gastos indebidos o superfluos. Alcanzar estos objetivos implicaría la ejecución de por lo menos tres programas: el nombramiento correcto de los altos mandos de la administración pública con funciones integradas y coordinadas, de tal manera que pudiera ejercerse sobre ellos un control eficaz. En segundo término, la implementación de procesos de selección de personal para que los empleados sean competentes y bien preparados; $y$, por último, la puesta en práctica de técnicas de planeación que permitiera tomar decisiones a partir de una información confiable y suficiente, cuestión que supondría la existencia de programas adecuados de investigación y de informes. Gordon Schaeffer no escondía su pesimismo: «En México todo esto es mucho pedir $»^{2}$. En todo caso, la única posibilidad de romper con estos vicios era una apuesta por la lenta pero ineludible modernización del país, proceso que asociaba al aumento de una industrialización que permitiría limar «la docilidad» del pueblo mexicano potenciando las exigencias de responsabilidad a sus gobernantes ${ }^{3}$.

El diagnóstico de Gordon Schaeffer no era nuevo ni desconocido. A comienzos de los cuarenta, Lucio Mendieta y Núñez, uno de los fundadores de la sociología mexicana ${ }^{4}$, publicó un voluminoso estudio sobre la burocracia. Desde su formación como abogado y en buena medida como antropólogo, Mendieta y Núñez llegó a conclusiones tan lapidarias como las de su colega norteamericano: «La incompetencia de la alta burocracia de extracción principalmente política, la falta de interés personal del burócrata en su trabajo, la indisciplina y la inmoralidad determinan la deficiencia de los servicios públi$\cos \rangle^{5}$. Los correctivos a esta situación no solo dependían de un adecuado sistema de selección del personal y de su control, sino de la creación de una nueva institucionalidad que desterrara prácticas inmorales. "Aun cuando no la justificamos, no podemos condenar completamente la inmoralidad de la burocracia, puesto que en último análisis, solo es reflejo de la inmoralidad ambiente [...]. Nadie tiene derecho a tirar a la burocracia la primera piedra, la podredumbre que afecta a parte de esta, no es sino muestra de una total podredumbre» ${ }^{6}$.

Ahora bien, ¿la corrupción es solo un problema de índole moral? Hace algunos años, Fernando Escalante Gonzalbo lanzó una sugerente propuesta

\footnotetext{
2 Gordon Schaeffer VII / 1 (México, 1955): 308 y 309.

3 Gordon Schaeffer VII / 1 (México, 1955): 310.

4 Véase Olvera Serrano, 2004.

5 Mendieta y Núñez, 1942: 306.

6 Mendieta y Núñez, 1942: 297, 296, 313 y 314.
} 
para aproximarse al estudio de la corrupción política, subrayando que ella podría ser entendida como «una mediación para salvar una brecha entre el orden jurídico y el orden práctico vigente socialmente». A partir de esta idea afirmó que el «verdadero problema de la corrupción no es una cuestión moral sino política: la corrupción es parte del orden social, reproduce sus formas, sus desigualdades y contradicciones». Este autor ensancha la mirada sobre este fenómeno al subrayar que el carácter de la brecha entre lo jurídico y lo real, «sirve para cubrir determinadas necesidades sociales que forman parte de un orden informal producido históricamente» ${ }^{7}$. Algunas parcelas de ese orden producido históricamente están presentes en los estudios de Mendieta y Núñez y Gordon Schaeffer, al indagar los vicios heredados de la administración virreinal y la manera en que fueron procesados en el siglo de la Independencia, y durante el proceso de reajustes administrativos destrabados por la Revolución de 1910.

Por otra parte, y como lo advierte Claudio Lomnitz, a pesar de existir cierto consenso en definir a la corrupción política como el aprovechamiento de una función pública para obtener beneficios particulares, generalmente transgrediendo las leyes; no es común entenderla como una categoría cultural, en el sentido de ir más allá de una definición técnica del término, para adentrarse en el significado que los discursos políticos y las prácticas sociales han otorgado a esta conducta social. La corrupción transita y contamina los ámbitos de lo público y lo privado en tanto espacios claramente diferenciados de la modernidad política. La noción misma de corrupción refiere a complicidad, discreción y secretismo ejecutada por viciosos ciudadanos que con sus conductas alteran y descomponen el ordenamiento político. El estado de «podredumbre» al que se refiere Mendieta y Núñez es un buen ejemplo de un diagnóstico construido sobre la idea de individuos que infectan los poderes públicos hasta reducirlos a entidades ineficaces e inmorales. La idea de una pureza nacional violentada por fuerzas externas e internas que amenazan la realización del «bien común», permitiría recortar fronteras físicas y mentales en el proceso de construcción de los Estados nacionales. En esta dirección, pensar la corrupción como una categoría cultural podría abrir brechas para indagar los problemas de la extranjería en México, en tanto necesidad de erigir valladares ante la potencial amenaza representada que «agentes extraños» invadiendo el cuerpo de la nación. Al tiempo que, desde aquella categoría también se podrían estudiar a «agentes internos» que cediendo a las presiones de los extranjeros o abusando de ellos, terminan siendo responsables

\footnotetext{
7 Escalante Gonzalbo XXX / 2 (México, 1989): 333 y 338.
} 
directos o cómplices en actos corruptos que debilitan las fuerzas de la nación fomentando el beneficio privado ${ }^{8}$.

Sobre estas bases, en este artículo propongo indagar la naturaleza, extensión y significados de prácticas de corrupción en el Servicio de Migración (SM) de México durante las primeras décadas posrevolucionarias. Interesa observar los sentidos de esa «brecha» entre lo legal y lo real, y sobre todo la manera en que las prácticas corruptas crecían al amparo de un ensanchamiento de las regulaciones migratorias, en un contexto en que la necesidad de ingresar o salir de país por parte de extranjeros, pero también de mexicanos, era valorada como una oportunidad para un enriquecimiento ilícito.

\section{LA DEBILIDAD INSTITUCIONAL}

Si bien la primera Ley de inmigración data de 1908 y al amparo de ella se creó el Servicio de Inspección de Migrantes, no fue sino hasta mediados de los años veinte en que se sentaron las bases de una estructura institucional para atender la migración en México. En realidad, la mencionada Ley estipuló que correspondería a la Secretaría de Gobernación controlar la admisión de extranjeros al país, y que esa admisión quedaría supeditada a cuestiones de orden moral y de salubridad. Se trató de una legislación extremadamente liberal que partía del supuesto de «la igualdad de todos los países y de todas las razas, no estableciendo un solo precepto especial para ciudadanos de alguna nación ni para individuos de raza determinada»9. Para velar por el cumplimiento de esta norma, se dispuso de un cuerpo de inspectores asentado en puertos y lugares fronterizos autorizados para el ingreso de pasajeros procedentes del exterior. Este Servicio estuvo formado por agentes auxiliados por delegados sanitarios y aduanales dependientes de agencias gubernamentales de antigua creación. Un año antes del estallido revolucionario, esta institución fue la encargada de regular el ingreso de extranjeros al país; aunque esta tarea tuvo escasa verificación práctica, puesto que la ley solo establecía que serían rechazados aquellos extranjeros con una notoria incapacidad en el orden moral o en el sanitario. No existía ningún instrumento que permitiera conocer las capacidades morales de los extranjeros, de manera que en este aspecto los rechazos debieron ser bastante excepcionales ${ }^{10}$. El SM en realidad fue creado para los controles sanitarios, y de manera particular para la vigilancia de in-

\footnotetext{
8 Lomnitz, 2000: 11-30.

9 Ley de Migración de 1908, Instituto Nacional de Migración, 2002: 109.

10 Landa y Piña, 1930: 9.
} 
migrantes originarios de China. En atención a esto, la vigilancia se extendió hasta los principales puertos de salida, en donde fueron destacados unos pocos delegados sanitarios que tenían la encomienda de evitar que portadores de enfermedades contagiosas abordaran barcos con rumbo a los puertos del pacífico mexicano ${ }^{11}$.

La Revolución de 1910 interrumpió la institucionalización de este Servicio, y una década más tarde las aproximaciones a los movimientos migratorios dieron un vuelco radical. La norma constitucional que derivó del proceso revolucionario se caracterizó por instituir restricciones y controles a actividades e inversiones extranjeras. Este sesgo alcanzó las políticas migratorias y entonces la proclamaba «igualdad de razas y naciones» comenzó a ser matizada. A través de distintas legislaciones (1926, 1930 y 1936) se implantó una política cada vez más excluyente y fiscalizadora en relación a los migrantes extranjeros, al tiempo que en estas nuevas preocupaciones quedaron incluidos los emigrantes nacionales, en un intento por controlar su salida para así cumplir con la obligación constitucional de velar por la protección y la seguridad de los trabajadores ${ }^{12}$.

Regular la exclusión a través de políticas de selección cuantitativa y cualitativa de las corrientes migratorias, obligó al despliegue de una estructura burocrática encargada de vigilar las fronteras, documentar a los inmigrantes, emigrantes y turistas, rechazar a los «indeseables», enfrentar con penas y castigos la «ilegalidad», instaurar sistemas de conteo para la creación de las estadísticas migratorias, establecer los espacios de gestión y reglamentar los mecanismos para la formulación de políticas migratorias. Es decir, poner los fundamentos de la administración de los flujos poblacionales que ingresaban y salían del país.

En los años veinte vivían en México casi 15 millones de personas, de los cuales unos 140 mil eran extranjeros. El aporte de la inmigración al total de la población no alcanzaba el 1\%, cifra de por sí reducida que contrastaba con la referida a la emigración. En el quinquenio 1924-1928, desde Estados Unidos, ingresaron al país para permanecer o para volver a emigrar algo más de 200 mil mexicanos ${ }^{13}$. Estos guarismos delinearon una política que comenzaba a institucionalizarse. México expulsaba más población de la que atraía, pero este fenómeno tenía además ciertas singularidades. La emigración de mexicanos se caracterizaba por una elevada tasa de retorno determinada por los ciclos agrícolas, pero también por los ciclos de la economía estadouni-

\footnotetext{
11 Téllez Girón, 1918. Valenzuela, c. 1922.

12 Véase Yankelevich, 2010: 207-254.

13 Landa y Piña, 1930: 22. Salazar Anaya, 1996: 99.
} 
dense. Es decir, se trataba de empleos temporales que cuando se conjuntaban con coyunturas de crisis económicas determinaban repatriaciones compulsivas de trabajadores que, devueltos a México, no hacían más que agravar las de por sí difíciles condiciones del mercado de trabajo nacional. Por otra parte, también en la década del veinte, el prohibicionismo en las políticas migratorias de Estados Unidos ${ }^{14}$ convirtieron a México en un territorio de tránsito de flujos internacionales interesados en ingresar ilegalmente al vecino país. El origen de estos flujos, básicamente de Europa oriental y de medio y extremo oriente, alimentó temores ante poblaciones poco deseables por sus características étnicas y por las actividades a las que se dedicaban. El miedo a «invasiones» de gente «inasimilable» involucrada en el comercio minorista, no tardó en despertar reclamos por competencias comerciales que muy pronto se manifestaron en fobias étnicas. De tal suerte que a las ya tradicionales movilizaciones antichinas ${ }^{15}$, se sumaron quejas por el incremento de nuevos «indeseables». Estas acciones cristalizaron desde finales de los veinte en prohibiciones al ingreso de una variedad de «razas» y naciones: negros, asiáticos, indostanos, judíos, gitanos, palacios, árabes y libaneses, etc. Finalmente, estas prohibiciones condujeron al establecimiento de un sistema de cuotas de ingreso a partir de 1937, que se mantuvo hasta mediados de la siguiente década ${ }^{16}$.

Desde 1926 y a lo largo de sucesivas legislaciones, se fueron estableciendo dispositivos legales cada vez más estrictos en relación al control, documentación y registro de nacionales y extranjeros que cruzaban las fronteras del país. Al amparo de estas regulaciones fue creciendo el aparato administrativo y, junto a él, un conjunto de prácticas que permitían saldar la brecha entre los nuevos marcos normativos y una realidad poco dócil al mandato de la ley.

La corrupción en los ámbitos migratorios aparece vinculada tanto a autorizaciones para el ingreso, para la residencia o la salida del país, como para las actividades a las que se dedicaron una parte de flujos migratorios. Las fronteras norte y sur eran las más transitadas y por tanto las de mayor propensión a corrupciones. Cada una de esas fronteras presentaba condiciones peculiares. En la de Guatemala, la incorporación de poblados de aquel país a la soberanía mexicana a partir del Tratado de Límites de 1882, generó con el paso del tiempo una verdadera confusión sobre la nacionalidad de los residentes, puesto que antiguos guatemaltecos convertidos en mexicanos nunca

14 Véase Higham, 1963. Fitzgerald 1996. M-Ngai, 2004. Zolberg, 2006. Ueda, 2011.

15 Véase Hu de Hart XXI (Tucson, 1980): 49-85. Gómez Izquierdo, 1991. Puig, 1992. Cardiel Marín, 1993. B. Craib, 1996. Ham Chande, 1997: 167-188. Chao Romero, 2010.

16 Véase Yankelevich, 2011. 
fueron documentados como tales. Sobre este sedimento se agregó un continuo flujo de trabajadores temporales a las fincas cafetales del Soconusco que se mezclaron con los descendientes de los afectados en 188217. A partir de los años veinte, el estatus legal de esos trabajadores y las condiciones de contratación y trabajo, dieron origen a conflictos y prácticas ilegales en que se vieron envueltos agentes migratorios, autoridades locales, indígenas guatemaltecos y empresarios chiapanecos. Por otra parte, la frontera norte, principal puerta de entrada y de salida de migrantes nacionales y extranjeros, presentó condiciones específicas relacionadas a la expansión de las llamadas «industrias del vicio» (cantinas, casinos, hipódromos, prostíbulos y tráfico de drogas) que vivieron un expansivo crecimiento desde que el gobierno norteamericano aprobó la ley que reguló la manufactura y distribución de drogas en 1914 (Harrison Act), y la que prohibió la producción y consumo de alcohol en 1919 $(\text { Volstead Act })^{18}$. El lado mexicano de la línea fronteriza dio cobijo a estas actividades, muchas de ellas producto de inversiones que hicieron norteamericanos de manera directa o en sociedad con mexicanos. De esta forma, «la industria del vicio» transitó un camino ambiguo en el que, por un lado, se intentó implementar medidas prohibicionistas acordes con la políticas moralizadoras de una parte de la elite revolucionaria; y, por otro lado, se practicó una tolerancia cómplice para con actividades ilícitas que reportaban sustanciales ingresos fiscales a los estados y territorios federales norteños ${ }^{19}$. Al cobijo de esta «industria» floreció todo tipo de corruptelas, y entre ellas un lugar sobresaliente lo ocuparon los abusos, extorsiones y atropellos cometidos desde las agencias migratorias.

De este modo, la institucionalización del SM a partir de la segunda mitad de los veinte, se produjo en un contexto surcado por cuatro vectores: un aumento del tráfico de inmigrantes extranjeros, producto de las prohibiciones norteamericanas; un incremento de salidas y de retornos de trabajadores mexicanos de Estados Unidos a consecuencia de las crisis económicas; una expansión de la «industria del vicio» en la frontera norte; y por último, disputas en la frontera sur a raíz de la indefinición en que residían nuevos trabajadores migrantes guatemaltecos y antiguos residentes guatemaltecos y sus descendientes convertidos en mexicanos a partir del Tratado de Límites de 1882.

\footnotetext{
17 Castillo, Toussaint y Vázquez, 2006: 201.

18 Recio XXIV / 1 (Cambridge, 2002): 21-42. Sandos XLIX / 4 (California, 1980): 621645.

19 Véase Taylor Hansen V / 5 (México, 2000): 33-37. Ceballos Ramírez, 2001. Márquez, 2007: 186-212. Chenillo Alazraki, 2010.
} 
PenURIas y QUimeras

A partir de 1926, el SM se convirtió en un Departamento de la Secretaría de Gobernación, con la responsabilidad de ejecutar el mandato de la Ley en materia de inmigración y emigración, elaborar las estadísticas así como un censo de los extranjeros residentes en el país. Esa dependencia con sede en la capital del país fue organizada en delegaciones, oficinas, agencias y subagencias distribuidas en los principales puertos de entrada y salida de migrantes. Hacia 1930 eran 14 delegaciones de las que dependían 37 agencias y subagencias. Por otro lado, funcionaban 5 oficinas regionales y una oficina central.

Delegaciones, agencias y oficinas del Servicio Migratorio Mexicano (1930)

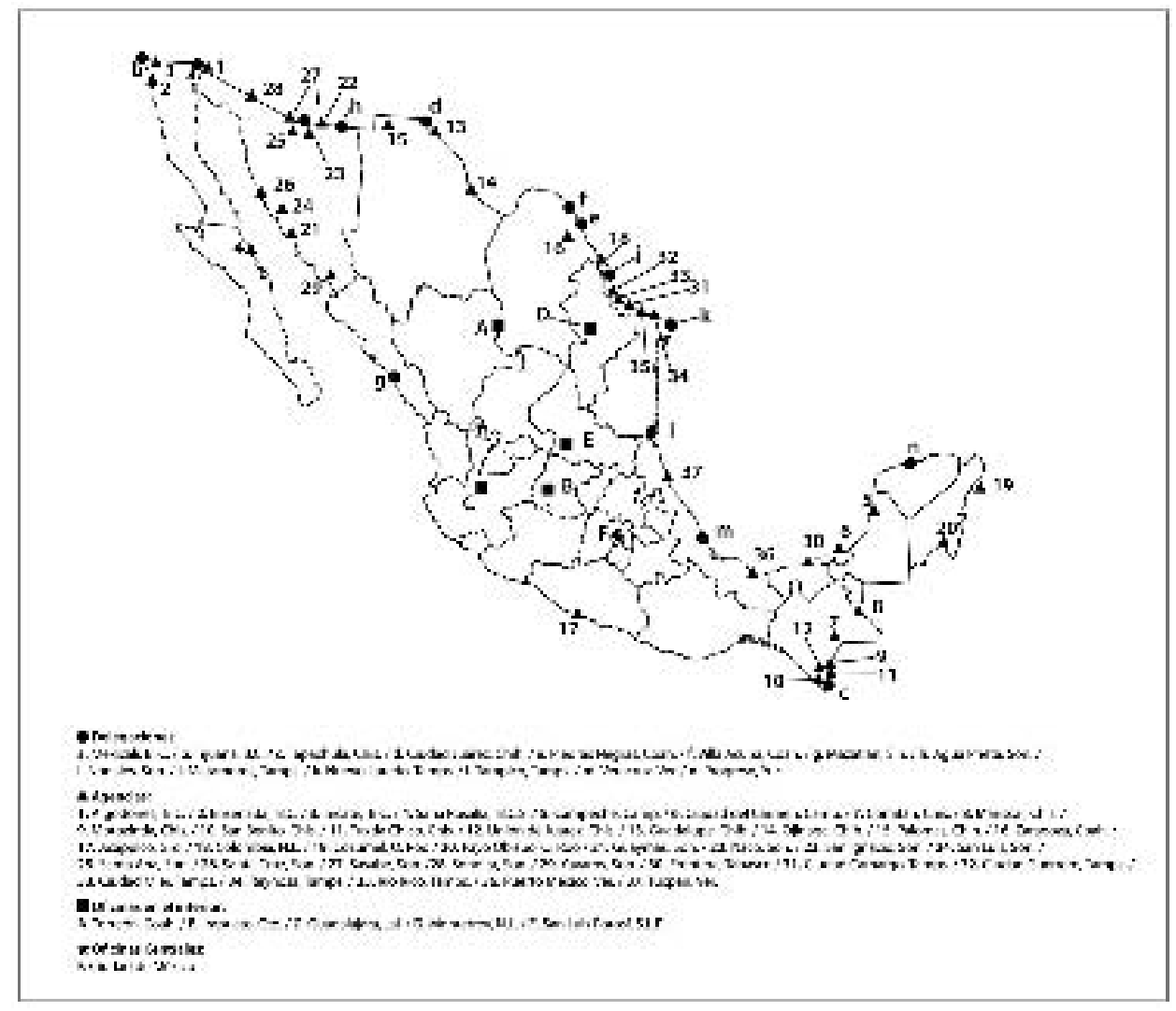


La zona norte del país concentraba la mayor parte del SM (11delegaciones y 23 agencias y subagencias). En segundo lugar, se ubicaban las de Chiapas y Quintana Roo atendiendo la frontera sur. La cadena se espaciaba en el Golfo, mientras que el Pacífico tenía una mínima representación en la estructura del SM. La importancia del problema emigratorio encuentra verificativo tanto en el número de agencias en el norte, como en que todas las oficinas estatales estuvieron localizadas en las capitales de estados con altas tasas de emigración.

En total trabajaban en el SM poco menos de cuatrocientas personas ${ }^{20}$. Muy pocas tenían alguna capacitación para las tareas que debían desempeñar. Los salarios eran bajos, las condiciones materiales malas y el equipamiento deficiente. Como no podía ser de otra forma, el espejo en el que las autoridades mexicanas miraban su SM era el de Estados Unidos. Solo la Border Patrol (Patrulla Fronteriza) instituida en 1924 como uno de los brazos del Bureau de Migración, contaba con cerca de 500 oficiales al concluir esa década. Un presupuesto de más de un millón de dólares al año, y una infraestructura operativa con abundantes recursos en materia de equipamiento, comunicaciones y transporte, colocaba a la Border Patrol en las antípodas del servicio mexicano ${ }^{21}$.

En marzo de 1929, Andrés Landa y Piña, entonces empleado de la Sección Estadística del Departamento Migratorio, recibió instrucciones de preparar un documento en que se detallasen las «deficiencias del Servicio de Migración». La solicitud hacía hincapié en profundizar en los principales problemas, entre ellos: la permanente introducción ilegal de inmigrantes, la necesidad de contar con un grupo de agentes de investigación para llevar adelante «las campañas moralizadoras contra el juego y la trata de blancas»; la incapacidad de «vigilar las corrientes de emigración»; la falta de oficinas y equipamiento y hasta de recursos para imprimir «las tarjetas de identificación que se proporciona a los inmigrantes»y, por tanto, la imposibilidad de realizar el registro nacional de extranjeros, obligación establecida en la legislación de $1926^{22}$.

Landa y Piña preparó un detallado informe dirigido a la Secretaría de Hacienda con copia a la Presidencia de la República. Se esperaba que una resolución del titular del Ejecutivo permitiera modificar un estado de cosas

20 Departamento de Migración, 12 de febrero de 1930; Archivo Histórico del Instituto Nacional de Migración, México (AHINM), Expediente 4/130 «1930»/823.

21 Masanz, 1980: 36. Para una aproximación a la historia de la Patrulla Fronteriza, véase Lytle Hernández, 2010.

22 Memorandum, 2 de marzo de 1929, AHINM, México, expediente 4/100 (07) 1929/94. 
signado por tres problemas: escaso personal, bajos sueldos y «cortedad en las partidas destinadas a sobresueldos, adquisición de muebles y útiles, gastos de pasajes, etc.». La cuestión de fondo era que el SM estaba incapacitado para velar por el cumplimiento de la ley. El personal y los recursos pecuniarios, indicaba Landa y Piña, «son de tal manera restringidos que vuelven impotente el menor esfuerzo y colocan al Servicio en condiciones que merman su capacidad de acción, y aún lo desacreditan». El problema era particularmente grave en la frontera norte, al hacerse manifiesto «el contraste de las condiciones dentro de las cuales actúan el Servicio Americano de Migración y el nuestro» ${ }^{23}$. Durante la década de los años treinta, las dos terceras partes de los empleados migratorios en México ganaban en promedio 5 pesos diarios (dólar y medio), el tercio restante tenía ingresos de casi 20 pesos diarios (cinco dólares y medio). Sucedía, «que los empleados norteamericanos de categoría secundaria en la línea fronteriza ganan tanto o más que el empleado de mayor categoría en las oficinas mexicanas» ${ }^{24}$. En efecto, los salarios del lado norteamericano fluctuaban según la categoría entre 6 dólares diarios en los niveles más bajos hasta 11 dólares diarios en los rangos superiores ${ }^{25}$. Las exiguas contrataciones y los bajos salarios explicaban la escasez de personal, asunto al que se agregaba el aumento del flujo migratorio y la apertura de nuevas vías de comunicación y de transporte. La combinatoria de estas circunstancias daba como resultado la cada vez más «frecuente introducción ilegal de extranjeros» ${ }^{26}$.

Por otra parte, la emigración de trabajadores mexicanos a Estados Unidos constituía un problema de dimensiones internacionales, sobre el que México estaba obligado a dar un respuesta, «si no para contener, por lo menos para regularizar esa migración». En teoría, se pretendía autorizar la salida de aquellos trabajadores que cumplieran las exigencias de la legislación norteamericana, para así evitar los peligros de cruces fronterizos por lugares no autorizados, y la explotación de la mano de obra nacional en condiciones inhumanas. Para la consecución de estos objetivos, era necesario establecer puestos de control a lo largo de las líneas ferroviarias que conducían al norte, así como oficinas de emigración encargadas de examinar a los emigrantes. La

23 Memorandum, 2 de marzo de 1929, AHINM, México, expediente 4/100 (07) $1929 / 94$.

24 Departamento de Migración, 12 de febrero de 1939, AHINM, México, expediente $4 / 130 \ll 1930 » / 823$.

25 Informe acerca de sueldos, 18 de marzo de 1929, AHINM, México, expediente 4/128/11-129/11.

26 Memorandum, 2 de marzo de 1929, AHINM, México, expediente 4/100 (07) $1929 / 94$. 
contención de esta migración debía, por otro lado, complementarse con una política de repatriación, que no solo contemplara el traslado de los migrantes hasta sus lugares de orígenes, sino la puesta en marcha de una política de colonización agrícola que permitiera la reinserción laboral de estos trabajadores. Sin embargo, «el Servicio de Migración está incapacitado para contribuir a la realización de un programa de repatriación de esta naturaleza, por la carencia de los elementos necesarios» ${ }^{27}$.

En resumen, concluía Landa y Piña, el Servicio «trabaja en condiciones que parecerían increíbles, se carece de muebles, de máquinas de escribir, de archiveros». No se disponía de locales propios para sus oficinas, estas se instalaron en locales de alquiler o en edificios pertenecientes a otras dependencias de la Federación. También se «carece en lo absoluto de autos, lanchas y aeronaves». El trabajo en condiciones tan precarias, ni siquiera permitía satisfacer las obligaciones básicas de controlar los ingresos y las salidas del territorio nacional.

El SM fue una instancia escasamente profesionalizada. En buena medida, el esfuerzo por crearlo y capacitarlo correspondió a Andrés Landa y Piña. Este michoacano, egresado de la carrera magisterial, se incorporó a mediados de los años veinte a la Secretaría de Gobernación; y desde los peldaños más bajos del escalafón, se vinculó al área de estadística, luego al Departamento Migratorio hasta llegar a dirigirlo durante la década del treinta. Este funcionario no fue un experto en cuestiones demográficas, se trató de un técnico que se especializó en asuntos migratorios a partir de la propia práctica y del apoyo de expertos a quienes convocó para escuchar opiniones. Landa y Piña fue de los pocos servidores públicos con un vasto conocimiento de la administración migratoria; en buena medida porque personalmente se involucró en todos los detalles de su organización; desde el diseño de las tarjetas de identificación de los migrantes hasta la promoción de instancias intersecretariales para la conducción de los asuntos migratorios.

Landa y Piña fue un funcionario convencido de la necesidad de moralizar y dignificar la agencia en la que trabajó y dirigió. Destaca el énfasis puesto en la conformación de un selecto grupo de cercanos colaboradores, reunidos en una instancia que llamó «mesa auxiliar de la jefatura» ${ }^{28}$, integrada por estudiantes o jóvenes graduados en abogacía, algunos traductores, y algún que otro periodista en los que depositaba toda su confianza, al igual que en algu-

27 Memorandum, 2 de marzo de 1929, AHINM, México, expediente 4/100 (07) 1929/94.

28 Oficio a la Jefatura, 6 de noviembre de 1932, AHINM, México, expediente 4/013-91931-1. 
nos inspectores que enviaba regularmente a «visitar» las oficinas a lo largo y ancho del país. Landa y Piña se esforzó por construir relaciones personales con la mayoría de los agentes del SM, escuchaba sus quejas y protestas, aconsejaba y protegía desde el convencimiento de que las experiencias en la diaria gestión de los empleados a su cargo debían traducirse en normativas que hicieran más eficiente el trabajo ${ }^{29}$. Por sobre todas las cosas, Landa y Piña pretendió forjar un espíritu de cuerpo entre sus subordinados. Se trataba de forjar una moral particular en el servidor público dedicado a atender los problemas migratorios: «es indispensable, llegó a escribir, que forjemos "un hombre", cuyo criterio se haga sentir de frontera a frontera, con inalterable exactitud, con inalterable justeza». Landa y Piña hablaba de un supuesto «hombre-tipo, con una actitud moral absoluta, presente en todos los momentos $\mathrm{y}$ en todos los rincones del país donde un caso migratorio deba resolverse» ${ }^{30}$. No cabe duda que detrás de ese modelo de funcionario estaba él mismo, sembrando su ejemplo de profesionalismo. Sin embargo, el espíritu de servicio público no fue la norma en el SM, en todo caso Andrés Landa y Piña y un muy reducido núcleo de colaboradores fueron la excepción.

\section{Abusos y alcoholismo}

En mayo de 1932, dos agentes de migración, los hermanos Everardo y José Luis Cárdenas, comisionados en Nogales, Sonora, abordaron un tren abarrotado de excursionistas norteamericanos rumbo a Phoenix y a Tucson. A poco de andar y «sin que mediara otra causa que el completo estado de ebriedad en que se encontraban, desenfundaron sus pistolas con ánimo de dispararlas». Empleados del Ferrocarril y de la oficina de Aduana pudieron desarmarlos, evitando «consecuencias más graves, ya que corrieron peligro las vidas de algunos viajeros de nacionalidad norteamericana, entre ellos, señoras, señoritas y niños» ${ }^{31}$. El caso tomó estado público, un editorialista preguntaba «¿Tendremos así turismo?, cuando quienes tienen el más grande deber de ser correctos y hospitalarios se lanzan como energúmenos con pistola en mano asuntando a mujeres y niños» ${ }^{32}$. El escándalo fue creciendo, la estación radial KWX de Nogales dirigió sus críticas a la agencia del SM por

\footnotetext{
29 Véase Yankelevich y Chenillo Alazraki, 2009: 187-230.

30 Consejo Consultivo de Migración, 4 de julio de 1931, AHINM, México, expediente 4-350-1930-448.

31 Excursionistas, 24 de mayo de 1932, AHINM, México, expediente 4/013-9-1932-15.

32 El Noroeste, Nogales, 25 de mayo de 1932: 3.
} 
haber dado empleo a individuos amorales, contratados por recomendaciones de funcionarios civiles y militares que se creen con autorización para constituirse en sultanillos» ${ }^{33}$. Entre tanto, la Cámara de Comercio de Nogales, Arizona, elevó su denuncia a la Secretaría de Gobernación. El escándalo no pudo disimularse y se ordenó una investigación que concluyó con la destitución de los agentes y una orden de arresto bajo los cargos de ebriedad, amenazas con armas de fuego y escándalo. Cuatro años más tarde la orden de aprehensión fue archivada, «en virtud de que el delito ya había prescrito» sin que la policía ministerial hubiera conseguido aprehender a los ex funcionarios ${ }^{34}$.

Las denuncias de alcoholismo eran constantes. En marzo de 1934, tres inspectores del SM fueron acusados por personal de Ferrocarriles Nacionales de ser responsables de causar desmanes a bordo de diferentes trenes. En un caso, Roberto Carreño y Santiago Tamayo, en un ferrocarril de México a Veracruz, se dedicaron a molestar a una mujer acompañada de su esposo de nacionalidad extrajera; «lo cual determinó que la dama se retirara del carro comedor, y cuando esto sucedió Carreño se dirigió al esposo, interrogándolo sobre su entrada al país y pidiéndole su tarjeta o documentos de migración». En vista de ser «notorio el estado de embriaguez en que se encontraba $\mathrm{Ca}$ rreño», se produjeron discusiones y altercados con el personal del tren, episodio al que se sumó el agente Tamayo quien, no menos alcoholizado que su compañero, «se había quedado dormido sobre una de las mesas del comedor». Las denuncias de la empresa ferroviaria ante la Secretaría de Gobernación condujeron a una investigación que muy pronto sacó a la luz un episodio similar protagonizado también por Carreño junto a otro empleado de migración, Alfonso R. Iñiguez, a bordo de un tren rumbo a Guadalajara, «ambos agentes se encontraban en estado de embriaguez y proferían palabras altisonantes en el carro de primera clase y en el Pulman, sin importarles las familias que en él viajaban». Hacia mediados de 1934, se decidió aplicarles un castigo a los tres agentes. En el caso de Carreño se fijo un descuento de cinco días de sueldo, mientras que en el de Tamayo e Iñiguez el descuento fue de tres días, además de incluir «una nota mala en el expediente de los agentes» ${ }^{35}$.

Los desmanes causados por personal de migración bajo los efectos del alcohol escalaban en intensidad e involucraban distintos niveles de la administración pública, poniendo en evidencia la subordinación de autoridades

\footnotetext{
33 Excursionistas, 23 de mayo de 1932, AHINM, México, expediente 4/013-9-1932-15.

34 Excursionistas, 1 de junio de 1932, AHINM, México, expediente 4/013-9-1932-15.

35 Ferrocarriles Nacionales, 19 de mayo de 1934, AHINM, México, expediente 4/0139-1934-31.
} 
municipales ante las arbitrariedades de agentes de la federación. A finales de 1937, David Escobar, técnico en refrigeración, recorría la frontera chiapaneca en cumplimento de su trabajo. En distintas poblaciones fue testigo de los atropellos protagonizados por cuatro agentes de migración que pistola en mano y alcoholizados abusaban por igual de inmigrantes chinos y de nacionales: «he presenciado, escribía al Secretario de Gobernación, una de las mayores desvergüenzas que nos desprestigia como nación». En Tapachula, Tuxtla Chico y Pueblo Nuevo agentes migratorios «completamente borrachos hasta caer, pistola en mano, echando balazos» abusaban de comerciantes chinos exigiéndoles sus tarjetas de identificación, al tiempo que visitaban cantinas y prostíbulos sin querer pagar sus consumos. Después de identificar a cada uno de esos servidores públicos, indicaba lo «más raro es que las autoridades no les hacen nada porque dicen que son federales, en cambio a los inditos, luego de que toman una copa, sin escandalizar ni nada, los llevan a la cárcel». Escobar concluía: ¿No le parece a usted, señor ministro que esa conducta es una vergüenza para nosotros y para el gobierno? $\gg^{36}$. La Secretaría de Gobernación no tardó en iniciar una investigación. Por una parte, solicitó informes a las autoridades municipales, entre ellas, el presidente del municipio de Tuxtla Chico quien de inmediato desmintió «que empleados federales hayan cometido algún atropello contra extranjeros o particulares. Siendo inexacto, afirmó, que el encargado del Servicio de Población de este lugar, se encuentre casi siempre en estado de embriaguez» ${ }^{37}$. En contraste, la propia Secretaría de Gobernación inició una investigación en la que resultó cierto todo lo denunciado. «Los cargos que se le hacen al agente Florencio Flores Gómez son justificados, informaba el jefe de la Comisión Demográfica Intersecretarial con sede en Tapachula, pues una vez tuvo que intervenir alguna persona de esta Comisión, para evitar que siguiera disparando balazos en la puerta del Hotel Berlín en donde estaba completamente ebrio, encontrándose este Hotel al frente de nuestras oficinas. Se tienen noticias de que los escándalos que comete en unión de Alberto Le Maire son muy frecuentes, y si no ha tomado intervención la policía es por la consideración que les tienen a los empleados federales». En relación a otros dos empleados, Mariano Pérez Sánchez y Enrique Mier Troncoso, si bien «acostumbran a libar con cierta frecuencia, no forman escándalos y no se les ven ligados a los que forman Flores Gómez». El caso llegó hasta la oficina de Manuel Gamio,

36 David Escobar, 9 de noviembre de 1937, AHINM, México, expediente 4/013-9-193787. 87.

37 David Escobar, 14 de diciembre de 1937, AHINM, México, expediente 4/013-9-1937- 
entonces Jefe del Departamento Demográfico de la Secretaría de Gobernación. En un informe a sus superiores hacía saber que si bien se había solicitado el cambio de oficina del más revoltoso de los agentes, puesto que Flores Sánchez «ponía un mal ejemplo entre los empleados que son cumplidos»; Gamio pedía que fuera cesado de inmediato, puesto que si no continuará «desmoralizando las oficinas en que está comisionado». Para los otros tres agentes solicitaba un «serio extrañamiento» con la advertencia de que se aplicarían severas sanciones en caso de reincidencia ${ }^{38}$.

Sembrar el mal ejemplo y desmoralizar las oficinas gubernamentales fueron argumentos socorridos en investigaciones e informes. Pocas veces recibían castigos los empleados que en lugar de velar por el «orden público» eran responsables del desorden. Razones prácticas fundadas en la ausencia de personal capacitado, en complicidades y favoritismos determinaban que muchas veces los castigos se limitaran a simples llamadas de atención, o en el mejor de los casos a una reubicación en otras oficinas del SM. Andrés Landa y Piña, desde la jefatura del SM, trataba de mediar entre los datos que arrojaban las investigaciones y la resignación de que con ese tipo de empleados debía forjar un «espíritu de servicio». Al observar sus reacciones ante las faltas administrativas y los delitos que cometía el personal a su cargo, se advierte una condescencia más cercana a un paternalismo pedagógico que al rigor en el ejercicio de una función pública. En mayo de 1931, Landa y Piña había recibido informes de que el jefe de la oficina de migración de Naco, Sonora, estaba dedicado a «embriagarse muy frecuentemente y sin ninguna discreción». Este funcionario recibió una misiva de Landa y Piña: "como su comportamiento redunda en el desprestigio de usted y a la vez de la oficina a su cargo, y contraría el concepto en que siempre lo he tenido, creo mi deber manifestar que, por el bien de usted mismo, debe evitar de modo absoluto la repetición de tales hechos» ${ }^{39}$. En esta misma dirección, apuntó en una carta dirigida al jefe de la oficina de Tecate, Baja California, sobre quien se denunciaba ausentismo: «de repetirse estas irregularidades, escribía Landa y Piña, sería preciso aplicar a usted un grave correctivo, prefiero ponerlo en antecedentes, suplicándole se abstenga de que tales hecho se repitan» ${ }^{40}$.

Las denuncias de mexicanos y extranjeros en contra del personal de migración exigían moralizar un servicio que avergonzaba a una nación gober-

38 David Escobar, 15 de diciembre de 1937, AHINM, México, expediente 4/013-9-193787.

39 Carta a Abelardo Apango, 22 de mayo de 1931, Archivo Andrés Landa y Piña, México (AALyP).

40 Carta a René Aguilar, 22 de mayo de 1931, AALyP, México. 
nada por funcionarios que, desde la ciudad de México, hacían públicas sus intenciones de «eliminar a todo elemento que no cumpliera con su cometido en lo referente a migración» ${ }^{41}$. Justamente en atención a estas declaraciones, un grupo de mexicanos residentes en Columbus, Nuevo México, escribieron al Secretario de Gobernación, Juan Cabral, exhortándolo a poner fin a la situación que se vivía en la oficina de Palomas, Chihuahua: «la mayoría de las veces que nosotros tenemos que pasar, los encargados no se encuentran en dicha oficina, no se imajina (sic) usted los trastornos que recibimos cada vez que pasamos a territorio mexicano, cuando no están borrachos, tenemos que pagar para que los llamen a sus casas. Según sabemos esos señores son compadres, por eso es que no hay orden en sus labores y se solapan uno al otro» ${ }^{42}$.

La corrupción era más visible en los funcionarios que estaban en contacto directo con el público. En las denuncias en su contra se exhiben cotidianas estrategias para la obtención de ingresos monetarios de manera ilícita. En diciembre de 1931, dos trabajadores mexicanos en Estados Unidos solicitaron en la oficina de migración de Ciudad Juárez un certificado que acreditara su condición de repatriados a los fines de ser eximidos de tasas aduanales para el ingreso de sus pertenencias. La empleada de esta oficina entregó un ejemplar del certificado cuando en realidad eran necesarios tres para completar el trámite ante las autoridades hacendarias. Los migrantes regresaron a la oficina a reclamar los tantos faltantes y fue entonces cuando la empleada exigió el pago de un peso por cada copia. Ante la negativa de pagar el «recargo»» exigido, los mexicanos optaron por elevar una denuncia por cobros indebidos. Las respuestas de los funcionarios de la agencia de Ciudad Juárez ante el interrogatorio de un oficial encargado de la investigación, trasluce la «naturalidad» de la práctica denunciada. Esperanza López, la empleada en cuestión, aceptó haber solicitado el soborno «porque es una costumbre establecida hace tiempo, y porque ve que los demás empleados hacen cosa igual». Interrogado otro empleado de la oficina ratificó que se trataba de una práctica consuetudinaria, aunque en su descargo aclaró que «esto no lo hacen con todas las personas sino únicamente con la gente que ven que traen dinero», aclarando además que el cobro que realizaban eran mínimo de compararse con las cantidades exigidas por gestores que apostados en las afueras de la oficina ofrecían sus servicios a los repatriados. La señorita López fue despedida, nada ocurrió con su compañero y para evitar «futuros problemas» se optó por so-

\footnotetext{
41 El Universal, México, 30 de septiembre de 1934: 4.

42 Palomas, Chihuahua, 19 de noviembre de 1934, AHINM, México, expediente 4/0139-1934-41.
} 
licitar al presidente municipal que apostara un oficial de policía en la puerta de la agencia migratoria, «a los fines de alejar a individuos pocos escrupulosos generalmente conocidos con el nombre de coyotes» ${ }^{43}$.

Los cobros «indebidos» eran la forma más común de abusar de migrantes y turistas extranjeros y nacionales, así como la más individual de las estrategias para allegarse recursos. La primera Ley de Migración de la posrevolución estableció la visa de turista, al tiempo que fijaba la obligatoriedad del registro de entrada y salida del país. A escasos meses de puesta en vigencia, a comienzos de 1927, el conocido cronista Jacobo Dalevuelta ${ }^{44}$ en un extenso reportaje periodístico informaba del atropello que cometían los agentes migratorios en Nuevo Laredo, Tamaulipas, al cobrar una «mordida de cincuenta centavos» por el pago de un arancel que ya había sido pagado en consulados mexicanos o en las oficinas centrales de migración ${ }^{45}$. El cobro de aranceles inexistentes a turistas a bordo de trenes o en retenes carreteros a lo largo de la frontera norte eran prácticas cotidianas: «un dólar era la cantidad que cobraba el señor inspector por cuidar el auto o por impuesto de piso» se indicaba en una investigación ordenada a raíz de la queja de un grupo de turistas norteamericanos en San Luis, Sonora. La forma en que «este empleado actuó, constituye un desprestigio para nuestro gobierno, que no tolerará que se siga extorsionando al turismo» quedó asentado en un documento interno del $\mathrm{SM}^{46}$.

\section{UN GRAN NEGOCIO}

La expansión de la corrupción era directamente proporcional al fortalecimiento de las normas de control y restricción. En consonancia, desde finales de la década del veinte quedó instalado en el discurso político la necesidad de combatir los abusos y extorsiones del personal encargado de la migración. A inicios de 1929, Ignacio García Téllez, entonces Oficial Mayor de la Secretaría de Gobernación, indicaba que «con toda energía la Secretaría ha reprimido los abusos cometidos por personal que disfrutaba de sus confianzas, se ha eliminado el "coyotaje" de personas que diciéndose influyentes tramitaban permisos para la entrada ilegal de extranjeros, $[. .$.$] intensificando$

43 Ciudad Juárez, Chihuahua, 7 de enero de 1932, AHINM, México, expediente 4/0139-1932-3

44 Seudónimo de Fernando Ramírez de Aguilar.

45 El Universal, México, 5 de febrero de 1927: 6.

46 San Luis, Sonora, 26 de febrero de 1932, AHINM, México, expediente 4/013-9-193211. 
la acción persecutoria a todos los elementos de corrupción administrativa» ${ }^{47}$. Seis años más tarde, Silvano Barba González, titular de la Secretaría de Gobernación, daba a conocer el inicio de una campaña contra «los coyotes que vienen explotando a los extranjeros» y en consecuencia anunciaba «la creación de oficinas a cargo de empleados absolutamente honorables y competentes» que atenderían de manera gratuita cualquier trámite en las oficinas de migración ${ }^{48}$. Y a mediados de 1942, ante las evidencias de cohechos y extorsiones, esa misma Secretaría anunciaba una completa depuración de los servicios de investigación a las actividades desarrolladas por residentes extranjeros, prometiendo contratar para tales fines a «personas de insospechable solvencia moral» ${ }^{49}$.

Los discursos caminaban en dirección contraria a la realidad. La Ley de Población de 1936, fue la más restrictiva que conoció México en materia de inmigración. En ella se regularon actividades, profesiones y lugares de residencia para los extranjeros interesados en residir en el país. Por las prohibiciones que estipulaba, llegó a señalarse que se trataba de una norma anticonstitucional, puesto que violentaba artículos de la Carta Magna que otorgaban a los extranjeros similares derechos que a los mexicanos, tales como la libertad de trabajo, de residencia, entre otros. Lucio Mendieta y Núñez, a la sazón consultor del Departamento Migratorio, defendió esta postura. La ley no solo era anticonstitucional sino además era impracticable e inmoral «porque cualquiera que fuese el número de vigilantes, nunca sería suficiente para controlar a millares de extranjeros en cuanto a sus residencias y actividades». E inmoral, por el creciente número de «empleados y funcionarios, de camarillas de influyentes e intermediarios dedicados a extorsionar a los extranjeros $\rangle^{50}$.

La gestión de la migración se convirtió en un negocio asentado en una extensa red integrada por autoridades con distintos grados de responsabilidad en la estructura administrativa, que interactuaban con «coyotes», autoridades locales y nacionales, empresarios, abogados y con extranjeros residentes interesados en gestionar el ingreso de coterráneos. A comienzos de 1932, el inspector Javier Larrea recibió la instrucción de realizar visitas a las oficinas de migración en la frontera nororiental. Durante un par de semanas recorrió la zona y en puntillosos informes a Manuel Téllez, Secretario de Gobernación, dio cuenta del estado de cosas. En poblaciones en que habían sido

47 El Universal, México, 26 de marzo de 1929: 3.

48 El Universal, México, 2 de noviembre de 1935: 4

49 El Universal, México, 4 de julio de 1942: 5.

50 Consejo Consultivo de Población, 8 de agosto de 1937, AHINM, México, expediente 47350-1935-228B. 
clausurados espacios de juego y cantinas, advertía una casi nula afluencia de turistas. Desde Río Rico, Tamaulipas, indicaba «nada que valga la pena hay que informar a usted». Similar ambiente encontró en Reynosa, Tamaulipas, «desde que cerraron las dos casas de juego no hay turismo. Puede decirse que casi no tiene vida esta población sucia y polvorienta [...]. Nada notable hay que informar sobre los empleados de esta delegación, a quienes le hice notar la recomendación de usted de ser corteses con el público y cuidadosos en el desempeño de sus funciones». En Camargo, Tamaulipas, indicaba que la oficina estaba a cargo de un solo agente, y que debido a que entre el margen del Rio Bravo y la ciudad había una distancia de ocho kilómetros, «la vigilancia que puede hacer ese único empleado es nula, por lo que puede entrar y salir de nuestro país quien guste», aunque como descargo subrayaba, «Camargo es un lugar muerto no hay sino muy pocos visitantes y ningún turismo» ${ }^{51}$.

Muy distinta era la situación en Nuevo Laredo, Tamaulipas, «donde el número de turistas y de repatriados es grande». Allí el jefe de la delegación era Arnulfo de los Santos, vinculado al SM desde 1914, «aunque se separó del cargo en distintas oportunidades y ha vuelto a reingresar». Una de esas oportunidades fue para ocupar el puesto de jefe de la policía municipal en donde «hizo algún dinero. Este señor es un hombre rudo que habla muy poco o casi nada el inglés, es déspota con sus subalternos y agrio en general con el público, y que además se ausenta con gran frecuencia de la delegación, saliendo dos o tres días por semana de la población». En realidad, el principal problema consistía en que este funcionario era socio en una empresa de transporte que «prestaba sus servicios» a emigrantes nacionales. De los Santos era un «pollero» que en sociedad con Candelario Guajardo, un conocido contrabandista dueño de una flotilla de automóviles, junto a un inspector de ferrocarriles apellidado Noriega, responsable de expedir pasajes a repatriados, administraban un jugoso negocio que consistía en documentar desde la delegación a los emigrantes y transportarlos al punto de su destino en Estados Unidos. «El emigrante que acepta comprarle el pasaje a Guajardo encuentra toda clase de facilidades y aún de ayuda por parte de De los Santos, y por el contrario, el que rehúsa hacerlo diciendo que se internaría a Estados Unidos haciendo uso de los autobuses americanos, se le ponen todas las trabas para su salida del país». La complicidad de estos tres personajes incluía otros negocios, el primero eran los precios de los pasajes, mucho más caros que el transporte norteamericano, por ejemplo, «un pasaje de Laredo a Chicago

51 Javier Larrea, 19 de enero de 1932, AHINM, México, expediente 4/013-9-1932-18. 
cuesta 25 dólares en autobús y 39,50 dólares en los automóviles de Guajardo». Pero además, la misma flotilla de automóviles fue constituida a partir de un pingüe trato. Los autos se compraban a precios irrisorios a algunos repatriados a quienes se extorsionaba con el cobro de altos aranceles de importación. Ante la imposibilidad de hacer frente a esas tasas, se les ofrecía comprar los autos, y una parte del pago consistía en la entrega de pasajes en ferrocarril «dándoles Noriega los boletos a cargo de nuestro gobierno a toda la familia de los repatriados ${ }^{52}$.

La crónica de las visitas del inspector Larrea exhibe una taxonomía del $\mathrm{SM}$ en la frontera norte. Desde hacía unos pocos meses, la agencia de Matamoros, Tamaulipas, estaba a cargo de Daniel Z. Duarte a la sazón hermano político de uno de los subsecretarios de Gobernación. Años más tarde Duarte estuvo involucrado en hechos de corrupción; aunque en 1931 no había queja contra él, salvo lo que indicaba un informe «que desconocía por completo el funcionamiento de la oficina», por ello, había solicitado el traslado de un agente que estaba en funciones en la oficina de Camargo, Tamaulipas, ofreciéndole el puesto de subdirector. Sobre este individuo Larrea indicaba: «lo conozco desde 1929 en que era empleado de Compañía que explotaba el galgódromo en Camargo. Es muy amigo de los americanos que explotan el juego en la frontera norte, $[. .$.$] no creo que sea una persona a quien se le$ pueda tener confianza, y opino que sería necesario que sea cambiado a otra parte del país ${ }^{53}$. Lejos de solicitar la remoción de estos funcionarios, el correctivo consistía en cambiarlos de zona. La misma recomendación hizo ante el negocio que regenteaba Arnulfo de los Santos en Nuevo Laredo. Se pretendía romper complicidades trasladándolos «hacia lugares donde no tuvieran "intereses creados" 54 ; paliativo que ponía en evidencia la incapacidad de controlar los procesos de reclutamiento del personal. Así, por ejemplo, Larrea indicaba que en Villa Acuña, Coahuila, el jefe de la delegación Pedro Acuña había sido suspendido de su cargo en septiembre de 1931, y un año más tarde fue reinstalado, «a pesar de las conocidas relaciones de amistad y de antiguos vínculos labores en el galgódromo y casas de juego» ${ }^{55}$. A una estrecha red de complicidades garantizando lealtades políticas y posibilidades de enriquecimiento, se sumó a partir de los años cuarenta una estructura sindical que garantizó la inamovilidad de sus afiliados, a cambio de un nutrido comercio

\footnotetext{
52 Javier Larrea, 19 de enero de 1932, AHINM, México, expediente 4/013-9-1932-18.

53 Idem.

54 Idem.

55 Idem.
} 
de prebendas y favores entre las dirigencias gremiales y la alta burocracia política $^{56}$.

En un medio dominado por negocios de cuestionada legalidad, resultaban «naturales» los intercambios entre los agentes migratorios y los encargados o dueños de cantinas, casinos y prostíbulos. Entre otros casos, a comienzos de 1932, en Mexicali, Baja California, se inició una pesquisa por la denuncia de que «el cabaret Owl está proporcionando un subsidio mensual a la oficina de migración por prestación de servicios» ${ }^{57}$. Los «subsidios» se recibían a cambio de permitir el ejercicio de actividades prohibidas, el ingreso o salida del país sin la documentación o de eximir del pago de los aranceles. Pero también las «mordidas» servían para subsanar deficiencias presupuestarias. El control en los trenes en la rutas norteñas era realizado por agentes que «andan por los caminos 24 horas seguidas en cada viaje, y como no tienen cantidad alguna señalada para viáticos, la situación para ellos es difícil y peligrosa para el honrado cumplimiento de su deber $\rangle^{58}$. Se trataba de empleados mal remunerados, a los que el «cumplimiento de su deber» los orillaba al cohecho y la extorsión. Se trataba también de empleados poco capacitados que en la mayoría de los casos no hablaban inglés, y a los que permanentemente se recomendaba «estar uniformados en las horas de servicio» ${ }^{59}$.

Estos funcionarios que privatizaban el servicio público en beneficio de intereses personales eran la norma en la administración de la migración. La ley colocaba a emigrantes e inmigrantes en una situación de vulnerabilidad que era aprovechada por los encargados de velar por su cumplimiento. Las obligaciones estipuladas por el marco normativo, y las propias penurias presupuestales, estimularon ingeniosos mecanismos de extorsión y cohecho. La mordida no solo era cotidiana, sino, y sobre todo, era necesaria para cumplir con la ley.

En la frontera norte, Nuevo Laredo, la dimensión de los flujos de ingreso y egreso de nacionales y extranjeros convirtió a las oficinas de migración en un lugar codiciado. A mediados de los años treinta, tomó estado público la existencia de una vasta red de corrupción y negocios fundados en el uso privado de recursos públicos. Todo comenzó con la denuncia de un funcionario contra el jefe de la delegación, Rosendo Herrera, que en septiembre de 1937 había remplazado a Daniel Z. Duarte, antiguo jefe de la agencia de Matamo-

56 Medieta y Nuñez, 1942: 169-208.

57 Mexicali, Baja California, 23 de febrero de 1932, AHINM, México, expediente 4/0139-1932-9.

58 Javier Larrea, 19 de enero de 1932, AHINM, México, expediente 4/013-9-1932-18.

59 Idem. 
ros, que al poco tiempo había conseguido un ascenso como jefe del SM de Nuevo Laredo. Herrera cobraba una «cuota mensual» a los responsables de agencias y subagencias bajo la jurisdicción de la Delegación a su cargo. Daniel Vázquez Dávila, el denunciante, se había negado a pagar esta cuota que era exigida a manera de retribución por supuestas gestiones realizadas por Herrera para que Vázquez Dávila fuera reasignado a las oficinas de Monterrey. El conflicto creció y pronto se supo de otras transacciones. La más escandalosa fue que Herrera había establecido un provechoso negocio de cambio de divisas en las oficinas de la Delegación y en el servicio a bordo de los trenes. Obligaba a los turistas a pagar en dólares aranceles por visas y fianzas por repatriación, el cambio se realizaba con un enorme diferencial entre la compra y la venta (compraba a un valor de $\$ 1,05$ por dólar y vendía la moneda estadounidense a $\$ 3,60$ ). El capital de este negocio era extraído de los pagos que los turistas realizaban, pagos que muy irregular y desordenadamente se depositaban en la cuenta bancaria de la Secretaría de Hacienda. Con parte de esos recursos, Herrera aprovisionaba a los empleados de su oficina y a los asignados al servicio en los trenes convirtiéndolos en «sus agentes comerciales dedicados al cambio de moneda $»^{60}$. Estas denuncias fueron la puerta de entrada para conocer desfalcos de mayor envergadura por decenas de miles de pesos. Buena parte de los empleados de la Delegación obtenían «prestamos» tomados de los recursos recaudados y entre los beneficiados figuraba el antiguo jefe Daniel Z. Duarte, quien desde 1937 se había convertido en diputado federal por el Estado de Zacatecas. Desde la ciudad de México, Duarte ordenaba a su antiguo tesorero en Nuevo Laredo situar dinero en Texas para la compra de material para un rancho que se estaba construyendo. El encargado de las finanzas de la Delegación y el propio Herrera «por razones de lealtad» ${ }^{61}$ no podían negarse a los pedidos del ahora diputado, quien bajo la protección del fuero legislativo consiguió librar un proceso judicial, al que sí fue sometido Rosendo Herrera, a pesar de haber conseguido un amparo de la justicia federal, en el que consignaba ser «una víctima del excesivo celo que puso en el cumplimiento de su trabajo, sobre todo por la labor de depuración y saneamiento de las oficinas en las que encontró muchas irregularidades» ${ }^{62}$. 93.

60 Rosendo Herrera, 21 de marzo de 1928, AHINM, México, expediente 4/013-9-1938${ }^{61}$ Rosendo Herrera, 28 de marzo de 1928, AHINM, México, expediente 4/013-9-193893.

62 El Universal, México, 6 de mayo de 1938: 4. 
El afán de lucro no hacía distingos. Sin mayor reparo se extorsionaba a turistas y a inmigrantes extranjeros o emigrados nacionales. No fueron la excepción intentos de soborno a pasajeros mexicanos. A comienzos de diciembre de 1937, Luis Monroy Durán viajaba en ferrocarril al puerto de Veracruz, cuando un agente «que vestía uniforme del Servicio de Migración se acercó a preguntarme si yo era mexicano por nacimiento, a lo que contesté afirmativamente, sin poder probarlo puesto que no existen en nuestro país tarjetas de identificación. Como a juicio de este agente la exterioridad de mi físico no le pareció que correspondía a un mexicano, pretendió cobrarme una multa de 10 pesos, que rotundamente me negué a cubrir». Monroy Durán denunciaba esta situación ante el Subsecretario de Gobernación, agregando que el funcionario había conseguido cobrar la multa a otros tres pasajeros, «cuya nacionalidad desconozco, aunque los recibos que extendió no estaban impresos, y aunque tenían el sello de la oficina de migraciones, no estaban numerados $\rangle^{63}$.

En la frontera sur, las extorsiones tenían como destinatarios a empresarios cafetaleros y como víctimas a trabajadores guatemaltecos con años de residencia en México o a sus descendientes ya nacidos en el país. «Sucede señor Presidente, escribía un guatemalteco a Abelardo Rodríguez, titular del poder ejecutivo, que mientras no hay cosecha de café a nadie se molesta, pero en cuanto estas se aproximan se vuelven con furia contra nosotros las autoridades de migración consumando deportaciones bajo el pretexto de no estar registrados, o bien porque la mayoría de nosotros pertenecemos a las clases indígenas analfabetas, y no contamos con que justificar nuestra estancia en el país que data de hace muchos años. Es así como a últimas fechas se ha arrojado hacia Guatemala, con lujo de fuerza, a innumerables de mis connacionales.» Era claro que estas persecuciones obedecían al afán de los funcionarios de migración de «obtener fuertes sumas de dinero de los cafetaleros que nos necesitan para ayudar a levantar la cosecha». La misiva señalaba que en noviembre de 1934 se estaban realizando deportaciones en masa, «sacando a los trabajadores de las fincas que por mala situación financiera o por capricho no han cedido a las pretensiones del delegado de migración de Tapachula, quien manifiesta por todas partes que a nadie teme porque cuenta con el apoyo incondicional del general Juan Cabral, actual Secretario de Gobernación». Como prueba de esta situación se indicaban los nombres de los propietarios que había pagado hasta $\$ 3,60$ por trabajador, se trataba sobre todo de las fincas de alemanes que sin ningún reparo lo informaban a sus trabajadores

63 Luis Monroy, 9 de diciembre de 1937, AHINM, México, expediente 4/013-9-193788. 
para que no huyeran de las plantaciones. La carta concluía con una súplica: «Presidente, lance hacia nosotros una mirada. Esta es nuestra segunda Patria, no de ocasión sino de hace muchos pero muchísimos años» ${ }^{64}$.

Estas acusaciones fueron motivo de órdenes para que se investigara. En la mayoría de los casos se pedía información a las propias autoridades denunciadas, en otros, se enviaba a agentes especiales. Denuncias e investigaciones se sucedían rutinariamente, en pocas ocasiones se fijaban penalizaciones que en nada modificaban la situación. Los empleados corruptos eran reubicados en otras agencias, y quienes los remplazaban, muchas veces recibían instrucciones de abrir investigaciones sobre sus antecesores. En una estructura burocrática asentada en criterios de lealtad antes que de legalidad, no se podía más que exonerar culpas, relevar responsabilidades y eximir obligaciones. Se trataba de un sistema de reciprocidad en el que se permutaba lealtad por impunidad. En el caso referido, el responsable de la delegación en Tapachula casi de inmediato fue trasladado a otro destino, la Secretaría de Gobernación envío un agente a investigar, que en marzo de 1935 informó que las denuncias son «desde todo punto de vista falsas». El pago que habían hecho los finqueros no eran «mordidas» sino una retribución a los agentes migratorios por haberse trasladado a las plantaciones para registrar a los trabajadores guatemaltecos. El reporte remataba con la siguiente aclaración: «la información anterior no me consta, pero llegó a mis oídos al manifestarlo así los finqueros y peones de la región» ${ }^{65}$.

Si los guatemaltecos fueron presas fáciles de la venalidad del SM, en la costa noroccidental la migración de chinos y japoneses fue un impresionante negocio. A comienzos de la década de 1930, las prohibiciones en Estados Unidos a estas migraciones y las propias restricciones mexicanas, elevaban hasta 75 dólares el precio cobrado por las autoridades migratorias de Manzanillo para autorizar el desembarco de cada migrante japonés ${ }^{66}$. En tanto que para los chinos el costo podía alcanzar hasta 130 dólares por cabeza, según declaraciones de los involucrados en una red de tráfico de migrantes hacia Estados Unidos ${ }^{67}$. La corrupción en torno a los chinos reviste peculiaridades específicas más allá del «incentivo» que significaba la prohibición de su ingreso a México y a Estados Unidos. Las «mafias» chinas en ambos países

64 Manuel Ibarías Almegor, 8 de noviembre de 1934, AHINM, México, expediente 4/0139-1934-45.

65 Manuel Ibarías Almegor, 28 de marzo de 1935, AHINM, México, expediente 4/0139-1934-45.

66 Memorandum, 18 de junio de 1930, AHINM, México, expediente 4/360-130/8218.

67 El Universal, México, 1 de junio de 1931. 
tenían presencia en una serie de actividades delictivas: tráfico de drogas, de alcohol, juegos de azar, además de las propias rencillas entre «logias» enfren$\operatorname{tadas}^{68}$. De manera que el discurso en torno al «poder corruptor» del dinero chino con frecuencia fue esgrimido cada vez que salían a la luz los negocios entre autoridades migratorias e inmigrantes chinos. Estos últimos pagaban servicios que contemplaban desde autorizaciones para el ingreso al país de algunos de sus coterráneos, hasta la expulsión de miembros de la comunidad que por sus actividades económicas y políticas se convertían en incómodos competidores. Entre otros escándalos, a mediados de 1931 se conoció la existencia de una red de corrupción que gestionaba la expulsión de unos chinos y la protección de otros en la que estuvo involucrado el jefe del Departamento Confidencial de la Secretaría de Gobernación, agencia encargada de las investigaciones a extranjeros. Este funcionario, algunos de sus colaboradores y un grupo de chinos bajo los cargos de asociación delictuosa y cohecho fueron encarcelados por la justicia del Distrito Federal, al tiempo que el propio Jefe del Estado Mayor de la presidencia de la república, fue citado a declarar en una clara muestra de los alcances de la organización delictiva ${ }^{69}$. El proceso se extendió a lo largo de un semestre, hasta que a comienzos de 1932 todos los detenidos fueron puestos en libertad bajo el argumento de «no haberse comprobado los elementos constitutivos del delito» ${ }^{70}$.

Las transacciones ilegales alrededor de la migración china fueron de variada naturaleza. Algunas componendas salían al descubierto para convertirse en verdaderos escándalos, mientras que la corrupción en la cotidianidad de la gestión migratoria era materia de investigaciones internas realizadas por el propio SM. A mediados de 1930, en Nogales, Sonora, se advirtió «que el negocio de la entrada de chinos está aquí organizado de manera muy eficiente: agentes, consignatarios, guías, introductores, etc.» se apuntaba en un informe reservado. Estas mafias eran tan poderosas que habían llegado a imponer que el ingreso de orientales desde Estados Unidos se verificara solo por Nogales, «pues parece que debido a la bondad del negocio se había generado cierta competencia en otros lugares de ingreso y en consecuencia los precios habían bajado». En atención a estas circunstancias, el SM en aquella población fue «llamado al orden», y entre las medidas tomadas se decidió «propalar la noticia de que los chinos sin autorización para residir en el país serían deportados, mientras que los mexicanos que colaborasen en el negocio, serían con-

68 Para un acercamiento a estas logias, véase Cauich Carrillo, 2002.

69 El Universal, México, 3 de junio de 1931: 4.

70 Octava Sala, 12 de febrero de 1932, Archivo General de la Nación, México (AGN), Tribunal Superior de Justicia, folio 577050. 
signados ante las autoridades del Distrito Federal». Como parte de esta «campaña», Landa y Piña envió un mensaje al jefe del SM en aquella población: «me he enterado [...] que usted ha tenido alguna participación en el bochornoso asunto referente al contrabando de chinos. Deseo advertirle que en consideración a los antecedentes de usted, y para evitarle en esta ocasión cualquier pena, es preciso que corrija los errores que ha cometido». Al delegado en Nogales, "se le comunicaba que debía presentarse en la ciudad de México, en donde recibiría órdenes oficiales», presumiblemente se trataba de un nuevo destino. La carta concluía con un «reciba usted esta advertencia como inspirada en el deseo de ayudarlo y evitarle una más penosa situación» ${ }^{71}$.

La corrupción estaba presente en buena parte de la estructura del SM. Unas veces los sobornos eran solicitados por los funcionarios de migración, en ocasiones eran ofrecidos por intermediarios, aunque en la mayoría de los casos se advierte colusión entre funcionarios e intermediarios de distinta índole: gestores, empleadores, asociaciones comunitarias de inmigrantes, etc. Además, la corrupción en torno a la migración excedía los límites de la propia gestión migratoria para extenderse a autoridades en otros niveles de gobierno. Era frecuente que honestos funcionarios de migración tuvieran que enfrentar con poco éxito la nula colaboración de autoridades municipales en el combate a la ilegalidad en juegos de azar y venta de licores en que estaban involucrados extranjeros. Ramón Tirado, inspector de migración, a finales de 1930 daba cuenta de que el presidente municipal de Nogales, Sonora, solapaba estas actividades y protegía a sus promotores, y a cambio «recibe provechos pecuniarios» $\rangle^{72}$. Un año más tarde, el responsable de esa delegación solicitaba a la jefatura del SM el traslado a otra zona, ante las amenazas que había recibido por enfrentar a responsables del «negocio con los chinos», algunos de ellos empleados en la misma delegación ${ }^{73}$. Similares situaciones se observaban en otras regiones y con otras autoridades. Desde mediados de los años veinte, el encargado de la agencia del SM en Unión de Juárez, Chiapas, denunciaba la responsabilidad de algunos finqueros cafetaleros en el tráfico de trabajadores guatemaltecos, todo ello con la complicidad de autoridades municipales, estatales y las de la jefatura de la zona militar. «La agencia a mi cargo, tiene entablada abierta lucha contra los hacendados, y es

71 Carta a Agustín Rodríguez Portas, 23 de junio de 1930, AALyP, México. Para un acercamiento al tráfico de chinos a partir de la consulta de fuentes documentales norteamericanas, véase Douglas Taylor VI / 11 (Tijuana, 1994): 41-57.

72 Carta de Ramón Tirado, 5 de diciembre de 1930, AALyP, México.

73 Carta de firma ilegible, 23 de febrero de 1931, AALyP, México. 
lamentable tener que decir que los hacendados han sido reforzados con el apoyo de las autoridades locales.» Este funcionario glosaba la ley migratoria vigente, en cuyo artículo XI se especificaba que para hacer cumplir todas y cada una de sus disposiciones, los empleados de migración debían solicitar la ayuda de autoridades locales y federales. Ante ello preguntaba a Landa y Piña «¿Dónde está pues la ayuda que debería recibir?» ${ }^{74}$.

\section{PARA CONCLUIR}

Sin duda hubo empleados honestos en el SM, aunque la gestión de la migración delimita un espacio impregnado de corrupción. En agosto de 1942, un editorial periodístico indicaba: «las oficinas migratorias son cedazos en cuyas mallas se queda siempre parte del dinero de quienes pasan por ellas». Las denuncias y las condenas a la corrupción estaban extensamente instaladas en los discursos; haciendo evidente un consenso en torno a que esas prácticas lastimaban la imagen del gobierno y de la Nación. Aunque, por otra parte, y como sugería aquel editorial, en México se advertía una «normalización casi administrativa y socialmente sancionada de la inmoralidad». La normalidad de la «mordida» hacía de la corrupción una práctica tan común como necesaria, cuya presencia era endémica en la gestión de los asuntos públicos. No solo los extranjeros y los repatriados eran víctimas de extorsiones, también lo fueron funcionarios encargados de velar por el cumplimiento de la ley. El aumento de las regulaciones potenciaba la «inmoralidad», y cada esfuerzo por cumplir con las normas incrementaba la corrupción. Se trataba de un orden político y administrativo fundado en la costumbre más que en la legalidad. «Las mordidas han llegado a considerarse como anexas al sueldo que disfrutan los agentes. Se codician los cargos por la posibilidad de negocios que brindan $\rangle^{75}$. En este panorama, las normas jurídicas tenían poca autoridad, por ello no había respuesta a la pregunta de aquel agente: «¿dónde está la ayuda que debería recibir para cumplir con la Ley?». Se obedecía más a la autoridad que a la ley, la lealtad al jefe, al amigo o al compadre subordinaba la legalidad de las conductas. Muy al principio de su carrera como funcionario público, Andrés Landa y Piña calificó al SM como un «portero siempre malhumorado», una institución que en lugar de dar la bienvenida en nombre de la Nación, era «una traba al libre ejercicio del derecho de viajar, de repatriarse

\footnotetext{
74 Informe de Moisés Salcedo, mayo de 1929, AALyP.

75 El Universal, México, 1 de agosto de 1942: 5.
} 
y de inmigrar» ${ }^{76}$. No hay evidencia de «enriquecimiento ilícito» en el actuar de este hombre que dedicó buena parte de su vida a profesionalizar la gestión migratoria, como tampoco hay evidencia de que su esfuerzo haya rendido algún fruto. La corrupción permitió equilibrar pobres salarios, hizo posible que algunos funcionarios acumularan fortunas; también consintió que en distintos niveles de la burocracia estatal se anudaran vínculos clientelistas que tarde o temprano cristalizarían en respaldos políticos. Por último, la corrupción hizo posible que un heterogéneo universo de intermediarios mantuviera posiciones de poder.

La corrupción resultaba funcional a un sistema político fundado en lealtades personales, y estas lealtades, con absoluta naturalidad, atravesaban y contaminaban espacios públicos y privados. La función pública, convertida en una inagotable fuente de enriquecimiento, parecía inmunizada contra las permanentes campañas de «moralización». En realidad, la corrupción fue profusamente denunciada e investigada, muestra evidente de que constituía una preocupación; sin embargo, las acciones en su contra fueron inocuas. La falta de penalizaciones consagró a la impunidad y a la arbitrariedad como el canon de la conducta gubernamental. En suma, la «inmoralidad» reinante ayudaba a acortar la distancia entre el orden jurídico que obligaba a regular la presencia y el tránsito de inmigrantes y emigrantes; y una realidad que valoraba aquella obligación como una oportunidad para lucrar, para intercambiar favores, para construir fortunas y carreras políticas.

\section{REFERENCIAS CONSULTADAS}

Archivos

AGN. Archivo General de la Nación. México.

AHINM. Archivo Histórico del Instituto Nacional de Migración. México. AALyP. Archivo Andrés Landa y Piña. México.

\footnotetext{
76 Algunas observaciones al margen de la ley de migración, septiembre de 1927, AALyP, México.
} 


\section{BiBLIOGRAFÍA}

Escalante Gonzalbo, Fernando, «La corrupción política: apuntes para un modelo teórico», Foro Internacional, XXX / 2 (México, 1989): 328-345.

Cardiel Marín, Rosario, «La migración china en Baja California, 1877-1949», Tesis de Maestría, México, ENAH, 1993.

Castillo, Manuel Ángel, Toussaint Mónica y Vázquez, Mario, Frontera Sur. Espacios diversos, historia en común, México, SRE, 2006.

Cauich Carrillo, Fredy E., «La Asociación Masónica Chee Kung Tong y la comunidad china en la ciudad de México (1890-1943)», Tesis de Maestría en Humanidades, México, UAM, 2002.

Ceballos Ramírez, Manuel (coord.), Encuentro en la frontera: mexicanos y norteamericanos en un espacio común, México, El Colegio de México / El Colegio de la Frontera Norte / Universidad Autónoma de Tamaulipas, 2001.

Chande, Roberto Ham, «La migración china hacia México a través del Registro Nacional de Extranjeros», María Ota Mishima (ed.), Destino México: un estudio de las migraciones asiáticas a México, siglos XIX y XX, México, Colmex, 1997: 167-188.

Chao Romero, Robert, The Chinese in México, 1882-1940, Tucson, University of Arizona Press, 2010.

Chenillo Alazraki, Paola, «Mercurio contra Baco y Briján. Impuestos a la industria del vicio en Baja California norte, 1920-1940», México, Tesis de Especialización en Historia Económica, Facultad de Economía, UNAM, diciembre de 2010.

Craib, Raymond B., Chinese Immigrants in Porfirian México: A Preliminary Study of Settlement, Economic Activity and Anti-Chinese Sentiment, New Mexico, The University of New Mexico, 1996.

De Hart, Evelyn Hu, «Immigrants to a Developing Society: The Chinese in Northern México, 1875-1932», The Journal of Arizona History, XXI (Tucson, 1980): 49-85.

Fitzgerald, Keith, The Face of the Nation. Immigration, the State and the National Identity, Stanford, Stanford University Press, 1996.

Girón Telléz, Rafael, Inmigración y colonización en México, México, Imp. Victoria, 1918.

Gómez Izquierdo, José Jorge, El movimiento antichino en México (1871-1934), México, INAH, 1991.

Gordon Schaeffer, Wendell K., «La administración pública mexicana», Problemas Agrarios e Industriales de México, VII / 1 (México, 1955): 211-314.

Hansen, Douglas Taylor, «El contrabando de chinos a lo largo de la frontera norte entre México y Estados Unidos, 1882-1931», Frontera Norte, VI / 11 (Tijuana, 1994): 41-57. 
Hansen, Douglas Taylor, «Los casinos y el desarrollo de la ciudad de Tijuana, 19081935», Fronteras. Revista de dialogo cultural, V / 5 (México, 2000): 33-37.

Higham, John, Strangers in the land. Patterns of American Nativism 1860-1925, New York, Ateneum, 1963.

Instituto Nacional de Migración, Compilación histórica de la legislación migratoria en México, 1821-2002, México, Instituto Nacional de Migración, 2002.

Landa y Piña, Andrés, El Servicio de Migración en México, México, Secretaría de Gobernación, 1930.

Lomnitz, Claudio, «Introducción», Claudio Lomnitz (coord.), Vicios públicos, virtudes privadas: la corrupción en México, México, CIESAS, Miguel Ángel Porrúa, 2000: 11-30.

Lylte Hernández, Kelly, Migra! A history of the U.S. Border Patrol, Los Angeles, University of California Press, 2010.

Masanz, Sharon, History of the Immigration and Naturalization Service, Washington, G.P.O., 1980.

M-Ngai, Mae, Impossible Subjects: Illegal Aliens and the Making of Modern America, Princeton, Princeton University Press, 2004

Márquez, Graciela, «¿Modernización fiscal? Impuestos sobre bebidas alcohólicas, 1884-1930», E. Sánchez Santiró (coord.), Cruda realidad: producción, consumo y fiscalidad de las bebidas alcohólicas en México y América Latina, siglos XVIIXX, México, Instituto Mora, 2007: 186-212.

Mendieta y Núñez, Lucio, La administración pública en México, México, S.P.I, 1942.

Olvera Serrano, Margarita, Lucio Mendieta y Núñez y la institucionalización de la sociología en México, 1939-1965, México, UAM, 2004.

Puig, Juan, Entre el río Perla y el Nazas. La China decimonónica y sus braceros emigrantes, la colonia china de Torreón y la matanza de 1911, México, CONACULTA, 1992.

Recio, Gabriela, «Drugs and Alcohol: US Prohibition and the Origins of the Drug Trade in Mexico, 1910-1930», Journal of Latin American Studies, XXXIV / 1 (Cambridge, 2002): 21-42.

Salazar Anaya, Delia, La población extranjera en México (1895-1990). Un recuento con base en los Censos Generales de Población, México, INAH, 1996.

Sandos, James A., «Prostitution and Drugs: The United States Army on the MexicanAmerican Border, 1916-1917», The Pacific Historical Review, XLIX / 4 (California, 1980): 621-645.

Ueda, Reed (ed.), A companion to America Immigration, Oxford, Blackwell Publishing, 2011. 
Valenzuela, Francisco, Importancia de la inmigración en la República Mexicana, México, Mimeo, c.1922.

Yankelevich, Pablo, ¿Deseables o inconvenientes? Las fronteras de la extranjería en México posrevolucionario, México-Madrid, ENAH, Bonilla Artigas Eds., Iberoamericana/Vervuert, 2011.

Yankelevich Pablo y Chenillo Alazraki, Paola, «La arquitectura de la política de inmigración en México», Pablo Yankelevich (coord.), Nación y extranjería. La exclusión racial en las políticas migratorias de Argentina, Brasil, Cuba y México, México, UNAM-ENAH, 2009: 187-230.

Yankelevich, Pablo, «La inmigración: el ocaso de una utopía modernizadora», Ignacio Marván Laborde (coord.), Historia crítica de las modernizaciones en México, Revolución y reconstrucción, México, FCE-CIDE, 2010: 207-254.

Zolberg, Aristide R., A Nation by Design. Immigration Policy in the Fashioning of America, Cambridge, Harvard University Press, 2006.

Fecha de recepción: 24 de mayo de 2011

Fecha de aceptación: 21 de febrero de 2012

\section{Corruption and migratory management in post-revolutionary Mexico}

This work studies the nature, extension and significances of the corruption practices inside the Mexican Migration Service during the first decades of the $20^{\text {th }}$ century. In a context in which the need to enter or exit the country was seen, both by Mexicans or foreigners, as an opportunity for illicit enrichment, the article reveals how corruption practices flourished under the increase of immigration regulations. The pervasiveness of these practices allows one to assess them as a consubstantial part of the political order as opposed to an issue of a moral character.

KeY words: Mexico; immigration; corruption; public service; $20^{\text {th }}$ century. 